\title{
Delayed spontaneous alternation in lurcher mutant mice
}

\author{
ROBERT LALONDE, CHRISTIAN C. JOYAL, CHANTAL CÔTÉ, and M. I. BOTEZ \\ Hótel-Dieu Hospital, Montreal, Quebec, Canada
}

\begin{abstract}
Lurcher mutant mice alternated above chance at 0 -, but not at 3-and 10-min retention intervals, whereas normal mice alternated at all the retention intervals. These results are consistent with the hypothesis that the cerebellum plays a role in spatial memory, perhaps by means of cerebello-limbic and cerebello-cortical interactions. There were no differences between the groups either in an emergence test of anxiety or in an inclined screen test of motor coordination. These results indicate that lurchers show no disinhibitory tendencies in the emergence test and are not affected in all tests measuring motor coordination.
\end{abstract}

Lurcher mutant mice are characterized by a depletion of cerebellar Purkinje cells, granule cells, and inferior olive neurons (Caddy \& Biscoe, 1979; Wetts \& Herrup, 1982a, 1982b). In water-maze testing, spatial deficits have been found in this mutant, which agrees with the hypothesis that the cerebellum has a role in spatial orientation (Lalonde, Lamarre, \& Smith, 1988). A spatial deficit may underlie the lack of spontaneous alternation found in lurchers in a two-trial test (Lalonde, Lamarre, Smith, \& Botez, 1986), which is a single forced trial to the left or the right arm of a T-maze, followed by a choice trial in which the mouse either chooses the same arm or alternates. This test is used to measure basic spatial orientation processes and spatial memory (Lalonde et al., 1986) and is sensitive to lesions of the hippocampus (Isseroff, 1979) and other areas known to be involved in spatial learning (Lalonde \& Botez, 1990).

Spontaneous alternation deficits may also be caused by a defect in inhibitory processes (Lalonde et al., 1986). There is evidence that the cerebellum has a role in behavioral inhibition with other paradigms. Rats with paleocerebellar lesions did not perform as well as normal rats did in a differential response of low-rate schedule, an indication of disinhibitory tendencies (Kirk, Berntson, \& Hothersall, 1982).

The main goal of the present study was to attempt to distinguish between these two possible explanations for the spontaneous alternation deficit that has been found in lurchers (Lalonde et al., 1986). For this purpose, a twotrial test was devised at three retention intervals: 0,3 , and $10 \mathrm{~min}$. If the principal deficit is in spatial memory, as previously found in rats with hippocampal lesions (Isseroff, 1979), the deficit should appear after a delay but not in the condition with no delay. On the other hand,

This research was funded by the Canadian Association of Friedreich's Ataxia, DuPont Pharma, Parke-Davis (Canada), and NSERC. C.C.J. received a scholarship from the FCAR in Quebec. Address correspondence to R. Lalonde, Hôtel-Dieu Hospital, Neurology Service, Neurobiology Laboratory, Montreal, Quebec, Canada H2W IT8. a deficit in the no-delay condition would be indicative of disinhibitory tendencies, an extremely short-term memory, or an attentional defect. In addition, an emergence test was added for the purpose of discovering whether lurchers would emerge from a small chamber to an open field quicker than normal mice would-an alternate measure of disinhibitory tendencies, because rodents prefer enclosed rather than open spaces (Pellow, Chopin, File, \& Briley, 1985). An inclined screen test was also performed for the purpose of documenting spared and unspared motor coordination functions in this mutant. Lurchers have been found to be impaired in some tests (e.g., coat hanger) but not in others (e.g., wooden beam) (Lalonde, Botez, Joyal, \& Caumartin, 1992).

\section{METHOD}

\section{Subjects}

Twenty-eight lurcher mutant mice ( 17 females, 11 males) and 9 (5 females, 4 males) normal controls (B6CBACA-A ${ }^{w-5} / A$ ) were obtained at 1 month of age from the Jackson Laboratory (Bar Harbor, ME). They were kept in a temperature- and humidity-controlled room and were tested in a separate experimental room at 3 months of age.

\begin{abstract}
Apparatus
A T-maze $(81.5 \times 8.5 \mathrm{~cm}$; arms, $30 \times 8.5 \mathrm{~cm}$; height of walls, $10.2 \mathrm{~cm}$ ) made of transparent plastic was used. In the emergence test, a plastic container $(18 \times 12 \mathrm{~cm}$; height: $28 \mathrm{~cm})$ was placed on a steel table $(86 \times 45.5 \mathrm{~cm})$. The inclined screen measured $35 \times 35 \mathrm{~cm}$ (grid: 5 squares $/ \mathrm{cm}$ ), was placed on a chair at a height of $60 \mathrm{~cm}$ from the floor, and was covered with a blanket to cushion the falls of the mice. The screen was inclined at $40^{\circ}$.
\end{abstract}

\section{Procedure}

Spontaneous alternation test. On the first trial, the mice were placed into the stem of the T-maze with the right arm blocked. On the second trial, they could choose either to enter the same arm or to alternate. On odd days, the right arm was blocked and on even days the opposite arm was blocked. On Days 1, 4, and 7, the mice were immediately put back into the stem (after washing with water, at most a 10-sec delay, in order to reduce the possible effect of odor cues). On Days 2, 5, and 8, there was a 3-min delay (retention interval) between the forced trial and the test trial. On Days 3 , 
6,9 , and 10 (a fourth day was added to that interval in order to resolve the ambiguity of the significant value of one of the groups), there was a 10-min delay interval.

Emergence test. On Day 1, the mice were placed for $5 \mathrm{~min}$ in groups of 4-5 in the small chamber for purposes of habituation. A layer of plastic was placed at the entry during habituation and was removed during the emergence test. During Days 2-6, the mice were placed 1 at a time into the chamber, and the time taken for them to emerge to an open field (using two- and four-paw criteria) was measured (cutoff point: $300 \mathrm{sec}$ ). Each mouse had one trial per day, for five consecutive days.

Inclined screen test. On Day I (first day of alternation testing), the mice were placed on the inclined screen and three separate latencies were determined: the time elapsed before (1) they turned to face upward; (2) they reached the top of the screen; and (3) they fell (cutoff point: $120 \mathrm{sec}$ ). Whenever a mouse reached the top, that trial ended and a score of 120 was given for the third latency. Whenever a mouse fell, a value of 120 was given for the second measure. There were two trials during a single day of testing. There were 23 lurchers performing this test, instead of 28 .

\section{RESULTS}

The normal mice alternated above chance at all three retention intervals $\left[0 \mathrm{~min}, \chi^{2}(1)=4.48 ; 3 \mathrm{~min}, \chi^{2}(1)=\right.$ $4.48, p<.05$; $\left.10 \mathrm{~min}, \chi^{2}(1) 4.0, p<.05\right]$; lurcher mutants alternated at $0\left[\chi^{2}(1)=4.76, p<.05\right]$, but not at $3\left[\chi^{2}(1)=0.32, p>.05\right]$ or $10 \min \left[\chi^{2}(1)=0.57\right.$, $p>$.05] (see Table 1).

In the emergence test, there were no group differences (Wilcoxon rank sum) between the two- and four-paw criterion [inclined screen $=$ latency before reaching top: $\mathrm{R}(9,23)=108, p>.05$; emergence test $=$ four-paw criterion: $\mathrm{R}(9,28)=137, p>.05$ ] (see Table 2). In spite of ataxia, in the inclined screen test the lurcher mutants were able to turn around and reach the top of the screen as quickly as the normal mice were, and rarely fell off of the screen (see Table 2).

\section{DISCUSSION}

In the spontaneous alternation testing, the lurcher mutant mice alternated at the 0-but not at the 3- or 10-min intervals. In a previous study (Lalonde et al., 1986), lurcher mutants did not alternate in a two-trial test in which they were kept in the arm for $1 \mathrm{~min}$ during the forced trial. In the present study, the mutants were immediately placed back into the stem of the maze and were found to alternate above chance. The results of the present ex-
Table 1

Mean Percentages of Spontaneous Alternation Rate in Normal and Lurcher Mutant Mice

\begin{tabular}{cccc} 
& \multicolumn{3}{c}{ Retention Interval (Minutes) } \\
\cline { 2 - 3 } Group & 0 & 3 & 10 \\
\hline Normal $(n=9)$ & $70^{*}$ & $70^{*}$ & $67^{*}$ \\
Lurchers $(n=28)$ & $62^{*}$ & 57 & 54 \\
\hline
\end{tabular}

$* p<.05$ (chi-square test).

periment agree with the hypothesis that the spontaneous alternation deficit found in lurchers is due to a spatial memory or attentional defect, rather than a defect in behavioral inhibition. The results of the emergence test show that the lurcher mutants entered the open field at the same time as the normal mice did, therefore indicating no disinhibitory tendencies. Had the lurchers emerged more quickly, this would have been an indication of a lack of anxiety or a tendency toward disinhibition, because normal mice tend to be cautious, emerging slowly from a small compartment toward an open field. It may be that the lurchers would have emerged more quickly but were prevented from doing so because of ataxia. However, the lurchers had normal activity levels in $\mathrm{T}$-maze exploration (Lalonde et al., 1986), so we do not think that ataxia prevented them from an early departure. Instead, in this particular test of anxiety, the lurchers did not behave differently from the normal mice. This does not exclude the possibility of group differences in other tests of anxiety or neophobia. But in the present investigation, behavioral inhibition, as defined by perseverative responding in the no-delay condition of T-maze testing or by early emergence toward an open field, was not observed in the lurcher mutant mice.

At first glance, the lack of a group difference in the inclined screen test may see surprising, considering the obvious ataxic gait of these mutants. Previously, lurchers have performed well in some tests, including the wooden beam test. In the more challenging (using a $2-\mathrm{mm}$ thin steel bar instead of a $1-\mathrm{cm}$ thin wooden bar) coat hanger test, however, they were deficient (Lalonde et al., 1992). The lurchers were able to climb as well and as quickly as the normal mice, in spite of their hesitant gait, and managed to reach the top with few of them sliding and falling off.

Previously, we have tested lurchers in a multiple-trial version of spontaneous alternation and have found alter-

Table 2

Means $(M)$ and Standard Deviations $(S D)$ for the Emergence and Inclined Screen Tests With Normal and Lurcher Mutant Mice

\begin{tabular}{|c|c|c|c|c|c|c|c|c|c|c|}
\hline \multirow[b]{3}{*}{ Group } & \multicolumn{4}{|c|}{ Emergence Test } & \multicolumn{6}{|c|}{ Inclined Screen Test (Seconds) } \\
\hline & \multicolumn{2}{|c|}{ Two-Paw Criterion } & \multicolumn{2}{|c|}{ Four-Paw Criterion } & \multicolumn{2}{|c|}{ Latency 1} & \multicolumn{2}{|c|}{ Latency 2} & \multicolumn{2}{|c|}{ Latency 3} \\
\hline & $M$ & $S D$ & $M$ & $S D$ & $M$ & $S D$ & $M$ & $S D$ & $M$ & $S D$ \\
\hline Normal & 89.6 & 67.2 & 178.9 & 61.8 & 11.0 & 7.4 & 52.2 & 21.8 & 120 & 0 \\
\hline Lurcher & 99.9 & 73.7 & 141.8 & 82.1 & 11.8 & 13.9 & 41.2 & 26.8 & 117.9 & 9.6 \\
\hline
\end{tabular}

Note-Normal mice, $n=9$; lurcher mutants, $n=28$ for emergence test and $n=23$ for inclined screen test. Latency $1=$ time before turning, Latency $2=$ time to reach top of screen, Latency $3=$ time before falling. 
nation to be above chance (Lalonde et al., 1986). Moreover, the lurchers alternated above chance in a condition in which, on the first trial, they were constantly exposed to the same side over days (Lalonde et al., 1988). Together with the results of the present study in the no-delay condition, these data indicate that lurchers are able to inhibit responding to the inappropriate stimulus. This does not exclude the possibility of finding inhibitory defects in other tests. However, the present available data agree with the hypothesis that the cerebellum is involved in spatial memory (Lalonde et al., 1986). Human patients with cerebellar disease do not suffer from general amnesia, but this does not mean that specific functions such as spatial memory may not be impaired in such groups (Lalonde \& Botez, 1990). Learned alternation in a water maze is impaired in two other cerebellar mutants (weaver and staggerer mice), a result that is also congruent with the hypothesis of impaired spatial memory in animals with cerebellar disease (Lalonde, 1987; Lalonde \& Botez, 1990). Rats with cerebellar lesions caused by $X$-irradiation are also impaired in water-maze alternation tests (Pellegrino \& Altman, 1979).

The present results found for delayed alternation testing in lurchers differ from those of two other cerebellar mutants (weaver and staggerer) in that perseveration in the latter mutants was found, even with no delay (Lalonde, $1986,1987)$. This difference may be explained by various morphological abnormalities. Weaver mutants have fewer substantia nigra cells (Triarhou, Norton, \& Ghetti, 1988) and cerebellar granule cells (Hirano \& Dembitzer, 1973). Staggerer mutants resemble lurcher mutants in terms of a depletion of cerebellar granule cells, Purkinje cells, and inferior olive neurons (Blatt \& Eisenman, 1985; Herrup \& Mullen, 1979). There is also a reduction in deep nuclei weight in staggerers (Roffler-Tarlov \& Sidman, 1978), which has not been described in lurchers, where the deep nuclei are reported to be intact (Caddy \& Briscoe, 1979). It is our hypothesis that the cerebellum is involved, by means of cerebello-limbic or cerebello-cortical pathways (Lalonde \& Botez, 1990), both in spatial memory and behavioral inhibition, but the behavioral phenotype depends on the pattern and amount of neuropathology in the cerebellum and whether extracerebellar abnormalities are present. Spatial memory deficits could be caused by biochemical changes in limbic or neocortical areas secondary to cerebellar degeneration, as has been postulated to be the case for the neuropsychological impairments observed in human patients with heredo-degenerative ataxias (Botez, Gravel, Attig, \& Vézina, 1985; Botez, Léveillé, \& Botez, 1989). Thus, the cerebellum is conceived not as the locus of a spatial memory engram, but rather as a site modulating higher level brain centers involved in spatial memory (Lalonde \& Botez, 1990).

\section{REFERENCES}

Blatt, G. J., \& EISEnman, L. M. (1985). A qualitative and quantitative light microscopic study of the inferior olivary complex in the adult staggerer mouse. Journal of Neurogenetics, 2, 51-66.

Botez, M. I., Gravel, J., Attig, E., \& Vézina, J.-L. (1985). Reversible chronic cerebellar ataxia after phenytoin intoxication: Possible role of cerebellum in cognitive thought. Neurology, 35, 1152-1157.

Botez, M. I., LÉveillé, J., \& Botez, T. (1989). Role of the cerebellum in cognitive thought: SPECT and neurological findings. In M. Matheson \& H. Newman (Eds.), Rehabilitation: The path back (pp. 179-195). Richmond: Australian Society for the Study of Brain Impairment.

CADDY, K. W. T. , Biscoe, T. J. (1979). Structural and quantitative studies on the normal $\mathrm{C} 3 \mathrm{H}$ and lurcher mutant mouse. Philosophical Transactions of the Royal Society of London (Series B), 287, 167-201.

HerruP, K., \& MULLEN, R. J. (1979). Regional variation and absence of large neurons in the cerebellum of the staggerer mouse. Brain Research, 172, 1-12.

Hirano, A., Dembitzer, H. M. (1973). Cerebellar alterations in the weaver mouse. Journal of Cell Biology, 56, 478-486.

ISSEROFF, A. (1979). Limited recovery of spontaneous alternation after extensive hippocampal damage: Evidence for a memory impairment. Experimental Neurology, 64, 284-294

Kirk, W. T., Berntson, G. G., \& Hothersall, D. (1982). Effects of paleocerebellar lesions on DRL performance in the albino rat. Journal of Comparative \& Physiological Psychology, 96, 348-360.

LALONDE, R. (1986). Delayed spontaneous alternation in weaver mutant mice. Brain Research, 398, 178-180.

LALONDE, R. (1987). Exploration and spatial leaming in staggerer mutant mice. Journal of Neurogenetics, 4, 285-292.

Lalonde, R., Botez, M. I. (1990). The cerebellum and learning processes in animals. Brain Research Reviews, 15, 325-332.

Lalonde, R., Botez, M. I., Joyal, C. C., \& Caumartin, M. (1992). Motor abnormalities in lurcher mutant mice. Physiology \& Behavior, 51, 523-525.

LALONDE, R., LAMARRE, Y., SMITH, A. M. (1988). Does the mutant mouse lurcher have deficits in spatially oriented behaviours? Brain Research, 455, 24-30.

Lalonde, R., Lamarre, Y., Smith, A. M., \& Botez, M. I. (1986) Spontaneous alternation and habituation in lurcher mutant mice. Brain Research, 362, 161-164.

Pellegrino, L. J., \& Altman, J. (1979). Effects of differential inter ference with postnatal neurogenesis on motor performance, activity level, and maze learning of rats: A developmental study. Journal of Comparative \& Physiological Psychology, 93, 1-33.

Pellow, S., Chopin, F., File, S. E., \& Briley, M. (1985). Validation of open:closed arm entries in an elevated plus-maze as a measure of anxiety in the rat. Journal of Neuroscience Methods, 14, 149-167.

Roffler-Tarlov, S., \& Sidman, R. L. (1978). Concentrations of glutamic acid in cerebellar cortex and deep nuclei of normal mice and weaver, staggerer and nervous mutants. Brain Research, 142, 269-283.

Triarhou, L. C., Norton, J., \& Ghetti, B. (1988). Mesencephalic dopamine cell deficit involves areas A8, A9 and A10 in weaver mutant mice. Experimental Brain Research, 70, 256-265.

WetTs, R., Herrup, K. (1982a). Interaction of granule, Purkinje and inferior olivary neurons in lurcher chimeric mice: 1 . Qualitative studies. Journal of Embryology \& Experimental Morphology, 68, 87-98.

WetTs, R., Herrup, K. (1982b). Interaction of granule, Purkinje and inferior olivary neurons in lurcher chimeric mice: 2 . Granule cell death. Brain Research, 250, 358-362.

(Manuscript received November 2, 1992; revision accepted for publication January 14, 1993.) 